\title{
Effects of Mineral Adsorption on Subsurface Gas Transport
}

\author{
GUANGPING XU*AND JEFFERY GREATHOUSE
}

Sandia National Laboratories, Albuquerque, NM 87185, USA

(*correspondence: gxu@sandia.gov, jagreat@sandia.gov)

Field-scale studies of subsurface gas transport often do not take into account adsorption interactions between minerals and transported gases. These interactions are very sensitive to the mineral compositions and their pore structures and water contents (Paul et al. 2018 J. Environ. Radioact., $187,65)$. When different gases are preferentially adsorbed by different minerals, the observed gas composition at the surface may not be representative of the gas composition at the source of generation. Our goal is to evaluate gas adsorption behavior in subsurface environments using molecular-scale modeling and experiments of representative pure mineral phases.

The adsorption/desorption capability for noble gases (Ar, $\mathrm{Kr}$, and $\mathrm{Xe}$ ) by quartz, mordenite and clinoptilolite are measured experimentally. Before measurements, minerals were degassed at different temperatures to remove adsorbed water from the pore space. For clinoptilolite, there is only a slight increase in surface area from $14.7 \mathrm{~m}^{2} / \mathrm{g}$ when degassed at $27{ }^{\circ} \mathrm{C}$ to $18.8 \mathrm{~m}^{2} / \mathrm{g}$ when degassed at $150{ }^{\circ} \mathrm{C}$. Subsequent increments of the degassing temperature did not increase the accessible surface area. For mordenite, the specific surface area increased from $16.6 \mathrm{~m}^{2} / \mathrm{g}$ to $431 \mathrm{~m}^{2} / \mathrm{g}$ when the degas temperature increased from $27{ }^{\circ} \mathrm{C}$ to $350{ }^{\circ} \mathrm{C}$.

On a gravimetric basis, noble gas adsorption on mordenite or clinoptilolite was roughly 100 times more than on quartz, which is a proxy for non-zeolitic silicates. The important observation is that mordenite adsorbed more Xe than $\mathrm{Kr}$ (as expected), whereas more $\mathrm{Kr}$ than $\mathrm{Xe}$ was adsorbed in clinoptilolite. Our hypothesis, which is being validated by molecular simulation, is that gas adsorption capabilities will vary significantly depending on the gas properties as well as the pore size of the host rock. Gases will interact more strongly with mineral surfaces in very small pores due to confinement effects. In particular, when the pore size is similar to (or smaller than) the gas diameter, reverse selectivity can be observed, as was the case with our clinoptilolite results.

SNL is managed and operated by NTESS under DOE NNSA contract DE-NA0003525 